son, principalmente, bacteremias asociadas a catéteres en pacientes inmunocomprometidos y peritonitis en pacientes sometidos a diálisis peritoneal continua ambulatoria (DCPA) (3-5); no obstante, la infección en pacientes inmunocompetentes es muy rara $(6,7)$. Presentamos un caso de bacteriemia en un paciente inmunocompetente con un catéter venoso periférico.

Varón de 72 años que ingresa en nuestro hospital por angina de esfuerzo progresivo. Tres días más tarde es sometido a tratamiento trombolítico con urokinasa $\left(2 \times 10^{6} \mathrm{UI}\right)$ por presentar infarto agudo de miocardio. El periodo posinfarto se complicó con angina precisando de la administración prolongada de nitroglicerina intravenosa. En la segunda semana de ingreso, el paciente manifestó fiebre, escalofríos y signos de flebitis en la zona de entrada de un catéter (Abbocath) situado en el antebrazo. El recuento leucocitario fue de 10.000 leucocitos $/ \mathrm{mm}^{3}$ con un $85 \%$ de neutrofilos. A las 24 horas de retirar el catéter y tras la extracción de los correspondientes hemocultivos se inició el tratamiento empírico con amikacina $(500 \mathrm{mg} / 8 \mathrm{~h})$ y vancomicina $(\mathrm{lg} / 12 \mathrm{~h})$.

Las tres tomas de hemocultivos (Bactec System, Organon Tecnika) fueon positivas y subcultivadas en placas de agar sangre y agar chocolate incubadas a $37^{\circ} \mathrm{C}$ en atmósfera de aire y aire con $5 \%$ de $\mathrm{CO}_{2}$. En las placas crecieron colonias rugosas, amarillas, no hemolíticas de un bacilo gram negativo móvil. El microorganismo fue identificado como Flavimonas oryzihabitans usando las pruebas bioquímicas habituales, el sistema Api 20 y Vitek (bioMérieux, Francia). Se realizaron pruebas de sensibilidad a antibióticos mediante el método de difusión en disco y se determinaron las CMI's mediante E-test (AB Biodisk, Suecia). La bacteria fue sensible a piperacilina, aminoglicósidos, ciprofloxacina, ofloxacina, tetraciclina, imipenem, ceftazidima, cefpiroma y cefepima, y resistente a ampicilina, amoxi-clavulánico, cefoxitina, cefaclor, cefuroxima, cloramfenicol, aztreonam y cotrimoxazol. Tras conocer estos resultados y dada la persistencia de fiebre y escalofríos, se sustituyó la vancomicina por piperacilina-tazobactam $(4 \mathrm{~g} / 8 \mathrm{~h})$ durante catorce días. Cuarenta y ocho horas después del inicio del nuevo tratamiento la fiebre desapareció. Los hemocultivos obtenidos al concluir la terapia antimicrobiana fueron estériles.

La mayoría de los pacientes infectados por Flavimonas ory zihabitans tienen problemas clínicos suyacentes como intervenciones quirúrgicas recientes o algún tipo de inmunosupresión (enfermedad hematológica, cáncer, infección por VIH, diabetes) $(3,4,8,9)$. El caso expuesto representa una situación excepcional ya que la sepsis por Flavimonas oryzihabitans se produjo en un indivíduo sin deficiencias inmunológicas. Aunque no se envió el catéter para estudio microbiológico, consideramos que, probablemente, esta fue la puerta de entrada del bacilo al interior del organismo.

Flavimonas oryzihabitans es, generalmente, sensible a penicilinas, cefalosporinas de tercera generación, carbepenemes, aminoglucósidos, quinolonas y cotrimoxazol, resistente a cefalosporinas de primera y segunda generación, monobactames y glicopéptidos, y variable en su susceptibilidad a cloranfenicol (4). Sin embargo, la cepa aislada de la sangre de nuestro paciente fue resistente a cefalosporinas de tercera generación, aminopenicilinas, cloranfenicol y cotrimoxazol.

El paciente fue tratado con piperacilinaltazobactam durante dos semanas. Su evolución fue satisfactoria y los hemocultivos obtenidos una y dos semanas después del episodio febril fueron negativos.

En conclusión, Flavimonas oryzihabitans es un patógeno poco común que puede producir enfermedad en humanos, principalmente bacteriemia asociada a catéter en pacientes inmunodeprimidos, y peritonitis en pacientes sometidos a diálisis peritoneal contínua ambulatoria; no obstante, también puede causar enfermedad en pacientes sin deficiencias inmunológicas. El pronóstico suele ser bueno cuando se suministra un antibiótico adecuado, incluso aunque el catéter no sea retirado.
M. Treviño Castellano, A. García-Zabarte, E. Losada Arias*, C. García-Riestra, B. J. Regueiro García

Servicio de Microbiología. *Servicio de Medicina Interna. Com plejo Hospitalario Universitario. Santiago de Compostela

1. Holmes B, Stegertwalt AG, Weaver RE, Brenner DJ. Chryseomonas luteola comb. and Flavimonas oryzihabitans gen. nov. comb., Pseudomonas-like species from human. J Sys Bacteriol 1987; 37: 245-250.

2. Giraldi GL. Pseudomonas and related genera. En Balows A, Hauster WJ, Herrmann KL, Isenberg HD, Shadomy HJ. Manual of Clinical Microbiology. Washington. Am Soc Microbiol 1991: 429-441.

3. Lucas KG, Kiehn TE, Sobeck KA, Armstrong D, Brown AE. Sepsis caused by Flavimonas oryzihabitans. Medicine 1994, 73: 209-214.

4. Esteban J, Valero-Moratalla M, Icazar R, Soriano F. Infections due to Flavimonas oryzihabitans: Case report and review. Eur J Clin Microbiol Infect Dis 1993; 12: 797-799.

5. Verhasselt B, Claeys G, Elaichouni A, Verschragen G, Laureys G, Vaneechoutte M. Case of recurrent Flavimonas oryzihabitans bacteremia associated with an implanted central venous catheter: assesment of clonality by arbitrary primed PCR. J Clin Microbiol 1995; 33: 3047-3048.

6. Lam S, Isenberg HD, Edwards B, Hilton E. Community-acquired so-tissue infections caused by Flavimonas oryzihabitans. Clin Infect Dis 1994; 18: 808-809.

7. Munro R, Buckland G, Neville S. Flavimonas oryzihabitans infection of a surgical wound. Pathology 1990; 22: 230-231.

8. Kiris S, Over U, Babacan F, Lawrence R, Korten V. Disseminated FlaJimonas oryzihabitans infection in a diabetic patient who pted with suspected multiple splenic abscess. Clin Infect Dis 1997; 25: 3-325.

9. Mutters R, Kopler H, Krause TH. Isolation of Fítvfmonas oryzihabitans (CDC group Ve-2) from catheter-induced bacteremia ih an immunocompromised patient. Eur J Epidemiol 1990: 436-437.

\section{Impacto de la alarma de contaminación ambiental por ozono en un servicio de urgencias hospitalario}

\section{Sr Director:}

El ozono es un contaminante del aire ambiente de tipo oxidante. Su origen es fotoquímico, estimulándose su producción por efecto de la radiación solar. Niveles elevados de otros contaminantes como el óxido de nitrógeno e hidrocarburos también incrementan los niveles de ozono ambientales. La presencia de ozono atmosférico tiene una variación estacional, aumentando durante el mes de mayo al de septiembre, fechas en las que la radiación solar es mayor. En poblaciones industriales sigue una tendencia inversa al del resto de contaminantes ya que durante esas fechas la actividad industrial es menor. Debido a que se produce por efecto de la radiación solar, sus concentraciones son mayores de día que de noche. Los síntomas más frecuentes que producen en el organismo humano niveles elevados de ozono ambiental son irritación conjuntival, tos, dificultad respiratoria, cefalea y disminución de la concentración y de las capacidades físicas. Está demostrado que niveles elevados de ozono pueden producir un aumento de la morbilidad en pacientes con historia prévia de patología respiratoria y alérgica (1). Presentamos el caso de la repersusión sobre la frecuentación en un servicio de urgencias ante niveles elevados de contaminación por ozono. El miércoles 12 de agosto de 1998 del total de 46 estaciones con analizador de ozono de la Red Catalana de Vigilancia de la Contaminación Atmosférica, 35 se encontraban en funcionamiento y conectadas con el Departament de Medi Ambient de la Generalitat de Catalunya. De éstas, en un total de 9 detectaron niveleles superiores a $180 \mathrm{mcgr} / \mathrm{m}^{3} \mathrm{~h}$ : Terrassa $\left(191 \mathrm{mcgr} / \mathrm{m}^{3} \mathrm{~h}\right)$, Sant Cugat del Vallés (189 mcgr/m $\left./ \mathrm{m}^{3} \mathrm{~h}\right)$, Santa Perpétua de la Mogoda (221 $\left.\mathrm{mcgr} / \mathrm{m}^{3} \mathrm{~h}\right)$, Mollet $\left(190 \mathrm{mcgr} / \mathrm{m}^{3} \mathrm{~h}\right)$, Santa María de Palautordera $\left(194 \mathrm{mcgr} / \mathrm{m}^{3} \mathrm{~h}\right)$, Amposta $\left(202 \mathrm{mcgr} / \mathrm{m}^{3} \mathrm{~h}\right)$, Vic $\left(218 \mathrm{mcgr} / \mathrm{m}^{3} \mathrm{~h}\right)$ y 
Santa Pau (187 mcgr/m $\left.\mathrm{m}^{3} \mathrm{~h}\right)$. Protección Civil procedió a comunicar mediante FAX a los ayuntamientos de la zona y a los servicios de urgencias la situación. En nuestro hospital no adoptamos ningún dispositivo, estando en actitud expectante. En la figura I se muestra un diagrama de dispersión con la evolución del núnero total de urgencias durante 10 dias. Se aprecia una discretísima tendencia hacia el incremento del número de urgencias paralelo al incremento de niveles de ozono. Asimismo en la figura 1 se muestra que por especialidades atendidas, tan solo se aprecia una moderada tendencia hacia el incremento en las urgencias de Medicina Interna. El papel nocivo del ozono como contaminante han sido poco estudiado. Sus efectos parecen bien relacionados con incrementos de patología respiratoria, posiblemente al potenciar los efectos nocivos de otros contaminantes ambientales como el dióxido de nitrógeno y el dióxido de azufre (2-4). No queda claro que niveles de ozono elevados sean un factor que aumente la frecuentación en urgencias. Burtentt en un interesante estudio multicéntrico que agrupaba a 16 ciudades del Canadá (5), describe que el aumento de la hospitalización y niveles elevados de ozono varia de unas ciudades a otras, y que solo existia una diferencia estadísticamente significativa de abril a diciembre pero no en los meses de inviemo. Las autoridades sanitarias, siguiendo la directiva comunitaria 92/72 sobre contaminación atmosférica por ozono, informan de la detección de niveles elevados por encima de $180 \mathrm{mcg} / \mathrm{m}^{3} \mathrm{~h}$ produciéndose una situación de alerta cuando éstos sobrepasan los 360 microgramos $/ \mathrm{m}^{3} \mathrm{~h}$, en éste caso se reduce la circulación de vehículos y se restringen las emisiones de contaminantes industriales. En nuestro caso no apreciamos un incremento de la frecuentación hospitalaria que obligase a adoptar medidas especiales de atención a la población.

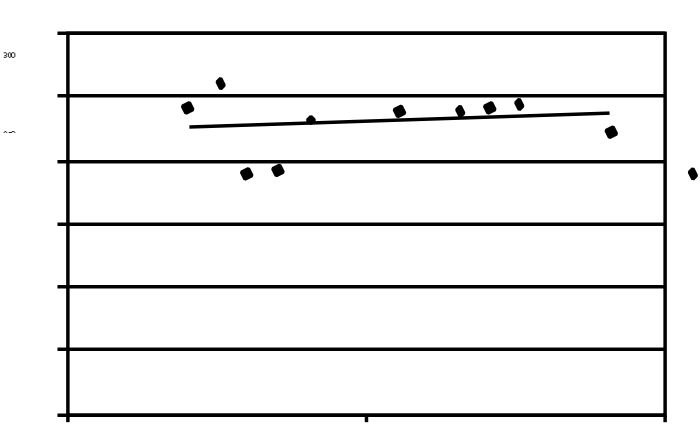

Fig. 1.

\section{F. Epelde-Gonzalo, S. Tomás-Vecina}

Servicio de Urgencias. Hospital Mútua de Terrassa. Tarrasa. Barcelona

1. Kunzli N, Kelly T, Balmes J, Tager IB. Reproductibility of retrospective asessment of outdor time-activity pattems as an individual determinant of long-term ambient ozone exposure. Int J Epidemiol 1997; 26: 1258-71.

2. Oehme FW, Coppock RW, Mostrom MS, Khan AA. A review of the toxicology of air pollutants: toxicology of chemical mixtures. Vet Hum Toxicol. 1996; 35: 371-7.

3. Ulmer C, Kopp M, Ihorst G, Frischer T, Foster J, Kuehr J. Effects of ambient ozone exposures during the spring and summer of 1994 on pulmonary function of schoolchindren. Pediatr Pulmonol 1997; 23: 344-53.

4. Dab W, Medina S, Quénel P, Le Moulle Y, Le Tertre A, Thelot B, et al. Short term respiratory health effects of ambient air pollution: Results of the
APHEA project in Paris. J Epidemiol Commutity Health 1996; 50: 42-6.

5. Bumett RT, Brook JR, Yung WT, Dales RE, Krewski D. Association between ozone and hospitalization for respiratory diseases in 16 Canadian cities. Environ Res 1977; 72: 24-31.

\section{Abdomen agudo como forma de presentación de enteritis eosinofílica}

\section{Sr. Director:}

La enteritis eosinofílica es una rara enfermedad caracterizada por la infiltración de cualquier tramo del tracto gastrointestinal, desde esofago hasta recto por células eosinófilas, aunque el estomago y el intestino delgado son las estructuras más frecuentemente afectas. Su etiología permanece desconocida, aunque de algún modo se ha implicado en su desarrollo la alergia a ciertos alimentos (1). Las manifestaciones clínicas varían en función de la región del tracto gastrointestinal afecto (2), y habitualmente presenta unas características crónicas, pero raras veces es causa de obstrucción intestinal. Presentamos el caso clínico de un paciente con abdomen agudo secundario a enteritis eosinofílica duodenal.

Varón de 38 años, con antecedentes de hipercolesterolemia y herniorrafia inguinal. Refería distensión e intenso dolor abdominal de tipo cólico de 2 días de evolución, asociado a anorexia, nauseas y vómitos, sin diarrea. También contaba episodios similares, aunque de menor intensidad, en los últimos seis meses. A la exploración se encontraba consciente y orientado, afebril, coloración normal de piel y mucosas. La auscultación cardiopulmonar fue normal, y el abdomen se presentaba distendido, difusamente doloroso a la palpación profunda y con ruidos hidroaereos muy disminuidos. Analíticamente mostraba un hemograma con 13.100 leucocitos sin desviación izquierda y $2 \%$ de eosinofilos, con perfil hemático y plaquetario normal. Bioquímica normal, y en la cuantificación de inmunoglobulinas destacaba: IgG 638 e IgE 887. Los coprocultivos fueron estériles no mostrando tampoco la existencia de parásitos en heces. La radiografia simple de abdomen mostraba la presencia de niveles hidroaereos. El rápido empeoramiento del estado general del paciente, precisó una intervención quinirgica inmediata, llevándose a cabo la resección de la segunda porción del duodeno. El estudio anatomopatológico de la pieza resecada y de biopsias tomadas de cuerpo y antro gástricos durante la cirugia, concluyó la existencia de enteritis eosinofílica. En el postoperatorio el paciente presentó algunos episodios pseudooclusivos que remitieron tras iniciar tratamiento corticoideo a dosis de $1 \mathrm{mg} / \mathrm{kg} /$ día, y una dieta libre de glutén y productos lacteos.

La enteritis eosinofílica fue descrita por primera vez por Kaijser en 1937, y constituye una entidad clínica poco frecuente (5) de la cual se han documentado menos de 300 casos en la literatura médica. Los criterios que definen este proceso son la presencia de síntomas gastrointestinales, la infiltración eosinófila de una o más areas gastrointestinales demostradas por biopsia, la ausencia de infiltrado eosinófilo de otras estructuras extradigestivas, y la ausencia de infestación parasitaria. La eosinofilia periférica no puede considerarse como criterio diagnóstico al encontrarse ausente en el $20 \%$ de los casos. Klein describió tres patrones diferentes de la enfermedad en base a una afectación predominantemente mucosa, que cursa como un síndrome de malabsorción, más comúnmente asociado a un antecedente de alergia alimentaria; otra, más raro, serosa que se manifiesta con ascitis e importante eosinofilia en el líquido ascítico; y una tercera con afectación de la capa muscular caracterizado por un importante engrosamiento y rigidez del estomago y de la porción proximal 